\title{
Sodium saccharin and sodium saccharin + sodium bicarbonate consumptions in rats: A comparison
}

\author{
ANDREW STROUTHES and ALFRED VOLO \\ State University of New York at Binghamton, Binghamton, New York 13901
}

\begin{abstract}
Seventy-three thirsty, hungry, or hungry and thirsty rats were given a choice between water and sodium saccharin in concentrations which were equivalent to the sodium saccharin component of a compound used in earlier studies (Strouthes \& Navarick, 1967; Strouthes, Volo, \& Unger, 1974) and which consisted of sodium saccharin and soda bicarbonate mixed in equal amounts. Intakes of sodium saccharin and sodium saccharin + soda bicarbonate under food- and water-deprivation conditions were markedly similar in pattern of drinking as well as in volumes consumed during the first 90 min of testing. When undeprived, rats tended to drink more sodium saccharin + soda bicarbonate relative to water than sodium saccharin. Thus, if these substances are offered in a choice with water, sodium saccharin + soda bicarbonate in concentrations used in these studies is entirely equivalent to sodium saccharin under a variety of deprivation conditions. The two substances, however, may not be equivalent for undeprived rats. The generality of earlier conclusions based on drinking of the compound may be extended to studies using just the sodium saccharin component.
\end{abstract}

In a series of experiments to study the deprivation effects of water (thirst), food (hunger), and of combined food and water on saccharin drinking in rats, we have used a compound consisting of half sodium saccharin (SS), $\mathrm{C}_{7} \mathrm{H}_{4} \mathrm{NNaO}_{3} \cdot 2 \mathrm{H}_{2} \mathrm{O}$, and half sodium bicarbonate (SB), $\mathrm{NaHCO}_{3}$. These two agents ${ }^{1}$, as a rule, are mixed in equal amounts to manufacture the common saccharin which sells in drug stores and supermarkets. We expressed the percent concentration values of the solutions in terms of $\left(\mathrm{SS}+\mathrm{SB} / \mathrm{SS}+\mathrm{SB}+\mathrm{H}_{2} 0\right) \times 100$. The concentrations we employed were $.1 \%$ and $1.0 \%$, values which are within the acceptability range of the rat. The results were unequivocal. It was found that thirsty naive rats in a 90-min choice between SS + SB (saccharin) and water, preferred water and drank more of it as a function of saccharin concentration. When the test was extended beyond $90 \mathrm{~min}$, the animals shifted to saccharin. The shift was inversely related to saccharin concentration (Strouthes, 1971; Strouthes \& Navarick, 1967). With experience, thirsty rats preferred saccharin (Strouthes, 1971). Hungry animals drank saccharin at the outset (Strouthes, Volo, \& Unger, 1974) though total intake was relatively small. Hungry and thirsty rats also preferred saccharin and drank small quantities of it, but only if they were equally hungry and thirsty, or if hunger exceeded thirst (Strouthes, Volo, \& Unger, 1974). Finally, undeprived rats, i.e., those which were neither hungry nor thirsty, almost always preferred saccharin but their intakes were indeed small (Strouthes \& Navarick, 1967; Strouthes, Volo, \& Unger, 1974).

In this study thirsty, hungry, and hungry and thirsty rats were given a choice of water and SS, in percent concentration values corresponding to those which constituted the SS component of the compound, $\mathrm{SS}+\mathrm{SB}$, used in two previous studies (Strouthes \&
Navarick, 1967; Strouthes, Volo, \& Unger, 1974). Its purpose was to determine the comparability of the two substances. It was prompted by concerns regarding the generality of the above findings to studies using sodium saccharin.

\section{METHOD}

\section{Subjects}

The subjects were 73 (70 male and 3 female) Sprague-Dawley albino rats, derived from stock originally purchased from Charles River, Massachusetts. They were 250 days of age at the start of the experiment and had no SS + SB or SS experience.

\section{Apparatus and Procedure}

The apparatus and procedures were the same as those used in the two earlier studies (Strouthes \& Navarick, 1967; Strouthes, Volo, \& Unger, 1974). Briefly, rats were tested in $24.5 \times 18 \times 19 \mathrm{~cm}$ stainless steel living cages, equipped with holes for insertion of two Richter tubes, one of which containted the solution, while the other contained deionized water. They were counterbalanced to control for side preference. A forced sampling procedure was used. It involved presenting singly, first one tube and then the other, each time until the 'substance was tasted. Withdrawal of the second tube was followed by simultaneous introduction of both tubes. Timing began when the rat licked one of the tubes following simultaneous introduction. Intakes were recorded every $10 \mathrm{~min}$ for a 90-min period. The rats were tested between 1:00 and 4:00 p.m. in an airconditioned vivarium $\left(21^{\circ} \mathrm{C} \pm 2^{\circ}\right)$.

Design 1 was a replication of the conditions of the Strouthes and Navarick study (1967) which used 110-day-old rats in a 2 by 3 factorial with hours of water deprivation, $0,24,48$ as one dimension, and .1\%, $1.0 \%$ SS + SB concentrations as the other. 2 The same design was used here with five male rats per cell and SS concentrations of $.05 \%$ and $.5 \%$. Design 2 was a replication of the conditions of the Strouthes, Volo, and Unger experiment (1974) which used 90- to 120-day-old rats in a 3 by 3 factorial. The two factors were 0,24 , or $48 \mathrm{~h}$ of food and 0,24 , or $48 \mathrm{~h}$ of water deprivation and the groups were labeled XH-YT, where X and $\mathrm{Y}$ represent hours of food and water deprivation, 


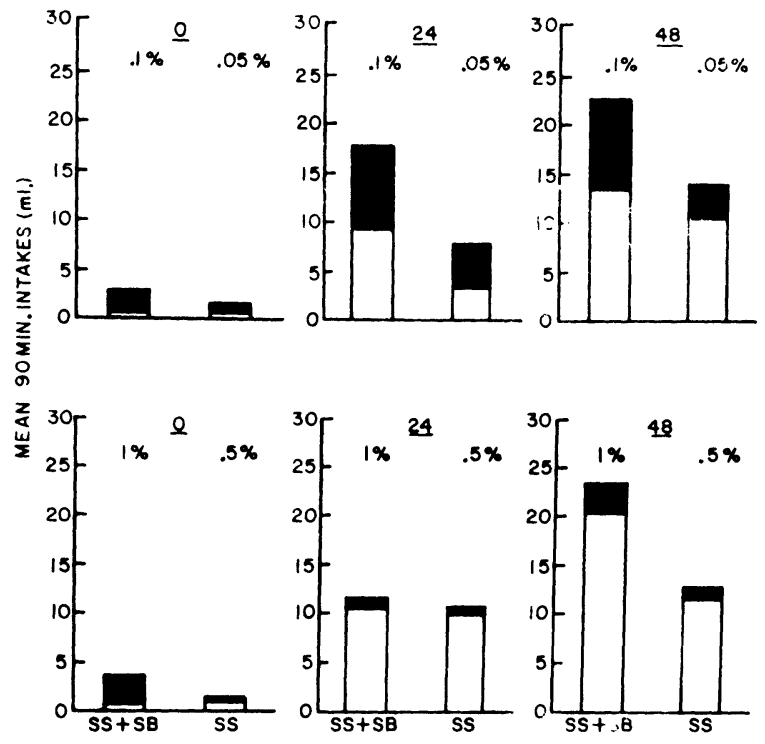

Figure 1. Mean 90-min intakes of SS + SB or SS (filled) and their respective water (open) from Strouthes and Navarick and the present study-Design 1.

respectively. Whereas, in the experiment by Strouthes, Volo, and Unger (1974), the solution was $1.0 \% \mathrm{SS}+\mathrm{SB}$, in Design 2 the solution was . $5 \%$ SS. Seven of the nine conditions in this design had five rats each; the remaining two conditions, $48 \mathrm{H}-24 \mathrm{~T}$ and $24 \mathrm{H}-48 \mathrm{~T}$, had four each.

\section{RESULTS AND DISCUSSION}

Figure 1 shows the mean $90-\min .1 \%$ and $1.0 \%$ $\mathrm{SS}+\mathrm{SB}$ and water intakes for the six groups of the original Strouthes and Navarick study and the $.05 \%$ and $.5 \% \mathrm{SS}$ and water intakes of the present study. Figure 2, similarly, displays $1.0 \% \mathrm{SS}+\mathrm{SB}$ and water intakes from Strouthes, Volo, and Unger and the current data based on $.5 \% \mathrm{SS}$ and water for each of the nine groups.

Design 1 saccharin (SS or SS + SB) intakes were analyzed with a 2 by 2 by 3 (substance by concentration by hours of deprivation) analysis of variance. The main effect of substance, which was of primary interest for this study, yielded an $F$ value of $8.34(\mathrm{df}=1,65$; $\mathrm{p}<.01$ ) indicating that $\mathrm{SS}$ and $\mathrm{SS}+\mathrm{SB}$ were not equivalent under some of the experimental conditions. However, paired comparisons between SS and SS + SB intakes under each of the six experimental conditions revealed no significant differences between the two substances under each level of concentration and deprivation. Similarly, Design 2 SS and SS + SB intakes were analyzed using a 2 by 3 by 3 (substance by food deprivation by water deprivation) analysis of variance. In this case, there was no significant effect of substance upon intakes $(\mathrm{F}=.008, \mathrm{df}=1,136)$, indicating an equivalent consumption of SS and SS $+\mathrm{SB}$ under the nine experimental conditions.

Although intakes of SS and SS + SB did not differ within any of the 15 groups, the possibility of differences in the relative proportion of saccharin to water consumption remained. In order to determine whether the pattern of saccharin and water drinking was the same for the two substances, saccharin and water intakes were converted to preference ratios $\left(\mathrm{SAC} / \mathrm{SAC}+\mathrm{H}_{2} \mathrm{O} \times 100\right)$ and analyzed in the same fashion as were the intakes.

In Design 1, the main effect of substance was again significant $(\mathrm{F}=6.05, \mathrm{df}=1,65 ; \mathrm{p}<.025)$. Paired comparisons this time revealed significant differences in preference ratios between $\mathrm{SS}$ and $\mathrm{SS}+\mathrm{SB}$ in groups $0-.1 \quad(\mathrm{~F}=4.42, \quad \mathrm{df}=1,65 ; \mathrm{p}<.05)$ and $0-1$ $(\mathrm{F}=13.57, \mathrm{df}=1,65 ; \mathrm{p}<.001)$, both of which were undeprived. Design 2 preference ratios were also analyzed in the same manner as intakes and the main effect of substance did not reach significance $(F=.009$, $\mathrm{df}=1,136)$. Therefore, $\mathrm{SS}$ and $\mathrm{SS}+\mathrm{SB}$ preference ratios, as well as intakes, did not differ under the conditons of Design 2.

In summary, SS and SS $+\mathrm{SB}$ offered in a choice with water were entirely equivalent in terms of intakes and preference ratios under all conditions where food and/or water deprivation were imposed. When nondeprived groups are considered, preference ratios for SS + SB were greater than for SS in Design 1, but did not differ in Design 2. The similarities between the patterns of intake of SS and SS + SB are remarkably strong, especially considering the differences between the animals used in the two conditions. The SS animals were 250 days old and were derived from the Charles River, Massachusetts stock noted, according to our records, for large body weights. The SS + SB rats were younger, 110 days in Design 1 and 90 to 120 days in Design 2, and were derived from Dan Rolfsmeyer, Wisconsin stock,

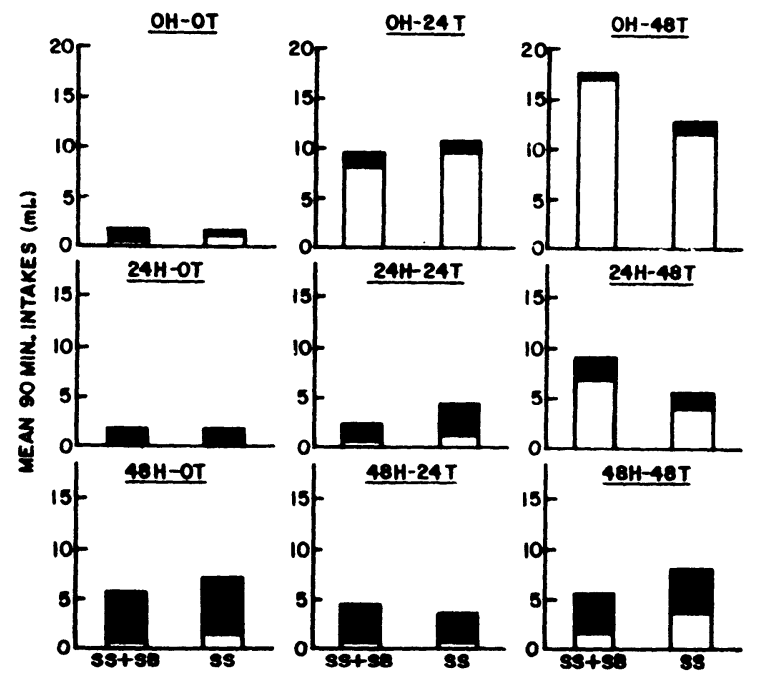

Figure 2. Mean $90-$ min intakes of $1.0 \% \mathrm{SS}+\mathrm{SB}$ or $.5 \% \mathrm{SS}$ (filled), and their respective water (open) from Strouthes, Volo, and Unger and the present study-Design 2. 
normally smaller animals.

Thus, it is generally concluded that under food and/or water deprivation, initial 90-min intakes obtained with one of these substances may be directly compared with intakes obtained with the other, providing, of course, that concentration values are properly adjusted and the substances are presented in a choice with water. The generality of earlier conclusions based on saccharin (SS + SB) consumptions (Strouthes, 1971; Strouthes \& Navarick, 1967; Strouthes, Volo, \& Unger, 1974) may be extended to studies using sodium saccharin (SS).

\section{REFERENCES}

Strouthes, A. Thirst and saccharin preference in rats. Physiology and Behavior, 1971, 6, 287-292.
Strouthes, A., \& Navarick, D. J. Saccharin and $\mathrm{H}_{2} \mathrm{O}$ consumption as a function of $\mathrm{H}_{2} \mathrm{O}$ deprivation. Psychonomic Science, 1967, 9, 523-524.

Strouthes, A., Voio, A. \& Unger, T. Hunger, thirst and their interactive effects on the rat's drinking in a saccharin-water choice. Physiology and Behavior, 1974, 13, 153-157.

\section{NOTES}

1. In the earlier studies, saccharin (SS + SB) was purchased in commercial tablet form from Norwich Pharmacal Co., Norwich N. Y. In later studies, we mixed the agents which were purchased from Fisher Scientific.

2. We thank David Litwack for assisting in the collection of Design 1 data.
(Received for publication May 9, 1974; revision received October 2,1974 .) 